\title{
A New Dental Superalloy System: I. Theory and Alloy Design
}

\author{
HAMDI MOHAMMED* and KAMAL ASGAR \\ School of Dentistry, University of Michigan, Ann Arbor, Michigan 48104 USA
}

Basic factors that influence the physical metallurgy and the mechanical properties of cobalt-base alloys are discussed in this study; these factors include the coherency of the interphase interface, the stacking fault energy, and the average electron hole number. Control of these factors and considerations of corrosion resistance and body compatibility determined the compositions for alloys that fulfill dental requirements.

Cobalt (Co)-base alloys are called superalloys because of their strength and stability at high temperatures. They also are called Stellites because of their resistance to corrosion. Although they have been used in dentistry since the 1930's, they are not fully accepted by dentists because they fracture during bending. Conventional Co alloys have ultimate tensile strengths that range from 85 to $120 \times 10^{3}$ psi and ductility that ranges from 2 to $4 \%$ elongation. The fracture of partial denture clasps may be caused by the lack of ductility rather than a lack of strength.

The purpose of this investigation was to produce a Co alloy system with the same strength properties and corrosion resistance as contemporary alloys, but with higher ductility ( $10 \%$ elongation), that work hardens at a slower rate and that is heat treatable and compatible with the human physiology. The theoretical considerations that precede the design and production of such a system are discussed.

Based on a dissertation submitted in partial fulfillment of the PhD degree in dental materials and engineering materials at the University of Michigan, 1971.

Part $I$ was presented at the 50th general meeting of the IADR, Las Vegas, Nev, 1972.

Received for publication May 14, 1972.

* Present address: University of Connecticut, Health Center, School of Dental Medicine, Farmington, Conn 06032 .

\section{Theoretical Considerations}

COHERENCY OF THE MATRIX-PRECIPITATE INTERFACE.-Precipitates can be classified according to the nature of the interface that is between the precipitate and the matrix. This interface can be coherent, semicoherent, or incoherent; it depends on how close the lattice parameters of the interface match those of the matrix. A schematic representation of these three types of precipitates is shown in Figure 1. If the match is exact (Fig 1,a), which is improbable, the boundary should have low energy. This coincidence of dimensions probably can be obtained only if some elastic distortion is introduced. For example, one crystal near the boundary could be stretched and the other could be compressed or it could be done by shear distortions. In the latter instance (Fig $1, b)$, the precipitate is semicoherent or coherent and the energy associated with the boundary is increased by the elastic coherency strains that are introduced.1,2 When there is no relationship between the matrix and the precipitate (Fig $1, c)$, the precipitate is incoherent and the boundary energy is low. The free energy of a system that is strengthened by coherent precipitation is higher than its energy when the precipitate is incoherent; coherent particles are smaller in diameter, larger in number, and less stable than incoherent particles.

When the precipitate is incoherent, ie, there is a larger distance between the particles, the dislocation probably would bow between its particles; there would be closed loops around them as shown in Figure 2. As each successive dislocation moves across the crystal, an additional loop is formed around each obstacle and the spaces between the obstacles decrease. The strength of a precipitation-hardened alloy is inversely proportional to the distance between the precipitate particle ${ }^{3}$; the formation of these 


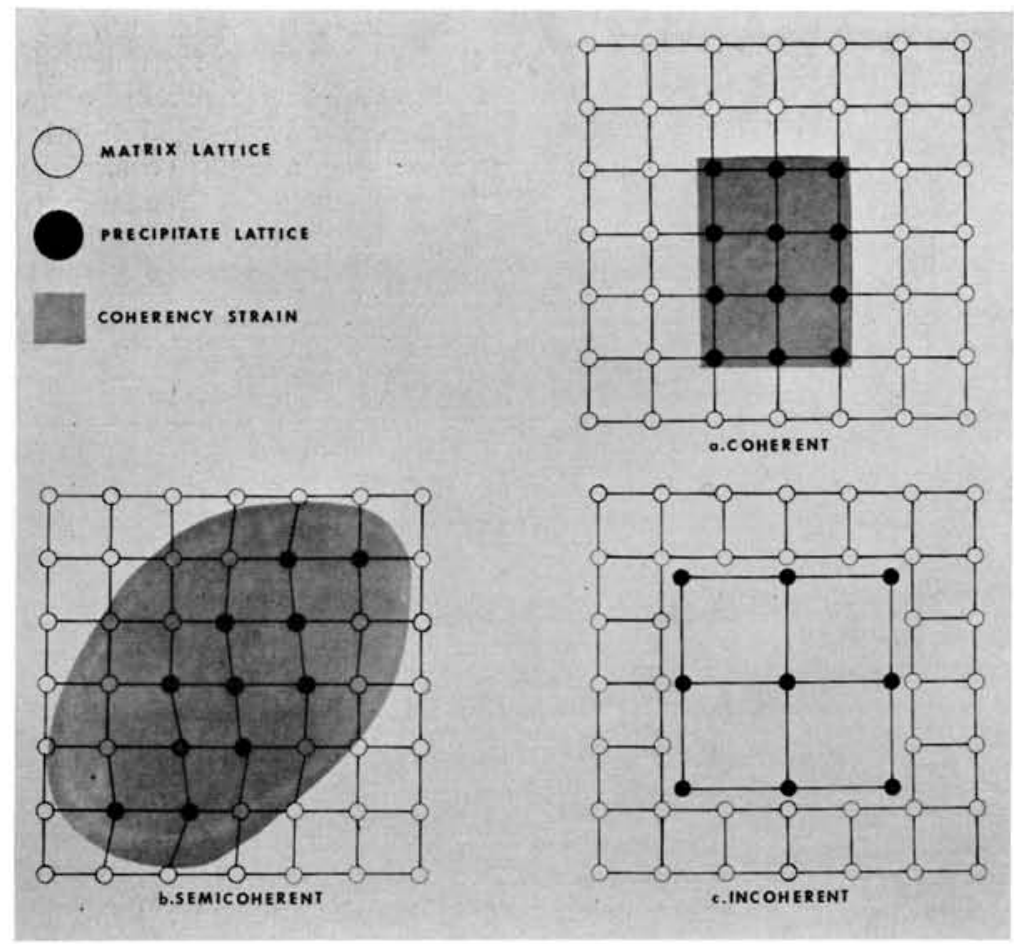

FIG 1.-Types of interfaces that form between matrix and precipitate.

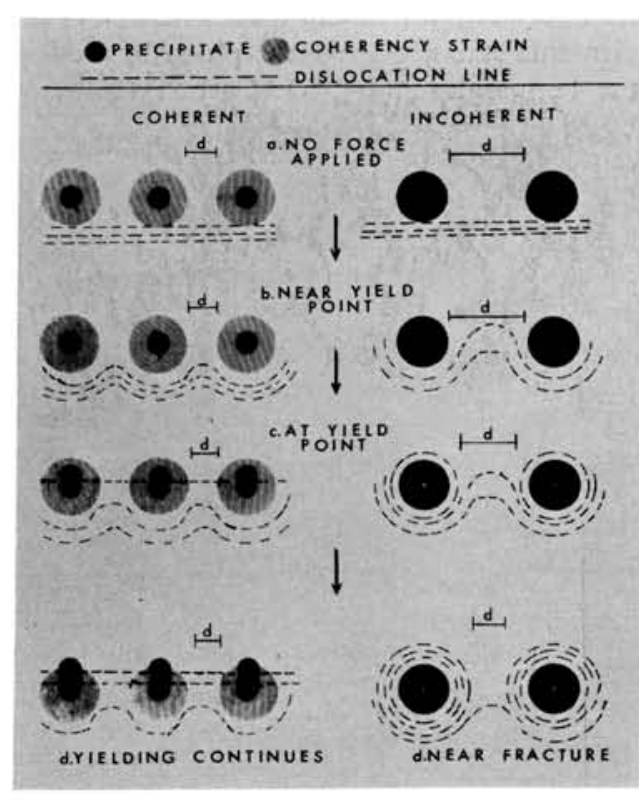

FIG 2.-Interaction between dislocation lines and various types of precipitate. loops makes it more difficult for additional dislocations to be forced in between. The formation of these loops around the precipitation particles causes a rapid rate of work hardening of the alloy. When the predominant precipitate is coherent, the small distance between the particles prevents the dislocation from bowing in between and work hardening is minimized. Ultimately, the proportional limit is reached and the stress is high enough so that the dislocation passes through the coherent particles by shearing them (Fig 2). The aforementioned mechanism indicates that higher stress is needed for an alloy yield if it is strengthened by a coherent precipitate, in comparison with its yield when the precipitate is incoherent. Coherency strains extend into an appreciable volume of the matrix, which enlarges the effective diameter of the coherent particles. This results in a smaller effective distance between the particles.

Coherent precipitates produce alloys of higher yield strength that work harden at 


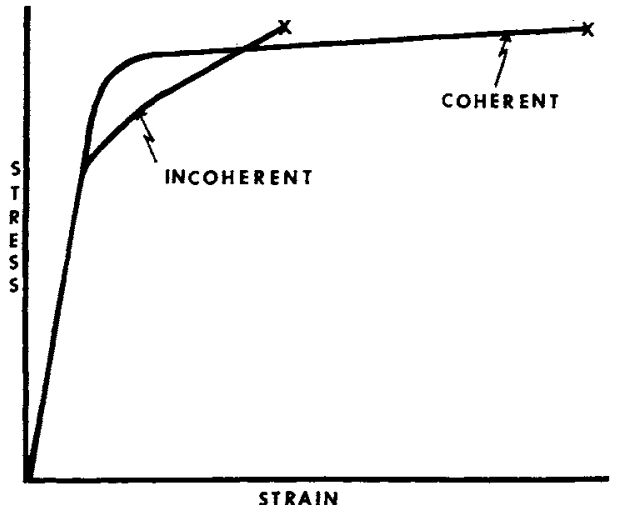

FIG 3.-Effect of various types of precipitate on stress-strain curve.

a slower rate. This affects the stress-strain curve in such a way that the same ultimate tensile strength can be achieved by either type of precipitate. When the latter is coherent, the alloy has a higher yield strength and more ductility. A schematic representation of these effects is shown in Figure 3.

Another advantage of coherent precipitates is that they can be transformed to semicoherent or incoherent precipitates by heat treatment. Such transformations change the mechanical behavior of the alloy. Alloys that are strengthened by coherent precipitates are expected to be heat treatable and to assume a range of mechanical properties.
STACKING FAULT ENERGY OF THE ALLOY SYSTEM.-Stacking faults are planar defects that separate two regions of good crystal, which differ by a rigid translation that is smaller than a lattice vector in the direction of translation..$^{3}$ A schematic representation of the ways in which the hexagonal closepacked (HCP) structure and the facecentered cubic (FCC) structure are stacked is found in Figure 4. In simple terms, a stacking fault is a small region of HCP structure in a continuous FCC lattice.

There are two allotropic modifications of Co: an HCP form, $\varepsilon$, that is stable at temperatures less than $417 \mathrm{C}$; and a FCC form, $\alpha$, that is stable at higher temperatures, up to the melting point of $1,492 \mathrm{C}$. The $\varepsilon \rightarrow \alpha$ transformation is sluggish because of the low free-energy change that is associated with the FCC to HCP transformation of Co. It was estimated ${ }^{4}$ from the transition temperature that the free-energy change was about 100 calories $/ \mathrm{gm}$. The effect of solute elements, which are added to strengthen the basic Co-chromium ( $\mathrm{Cr}$ )-nickel (Ni) alloy, on the temperature of the $\varepsilon \leftrightarrows \alpha$ transformation is important to this study. The influence of many solute elements has been systematically studied..$^{5,6}$ Some elements stabilize the FCC phase by lowering the $\alpha \rightarrow \varepsilon$ transformation temperature, whereas other elements stabilize the HCP phase by raising the temperature (Fig 5). Carbon (C), bo-
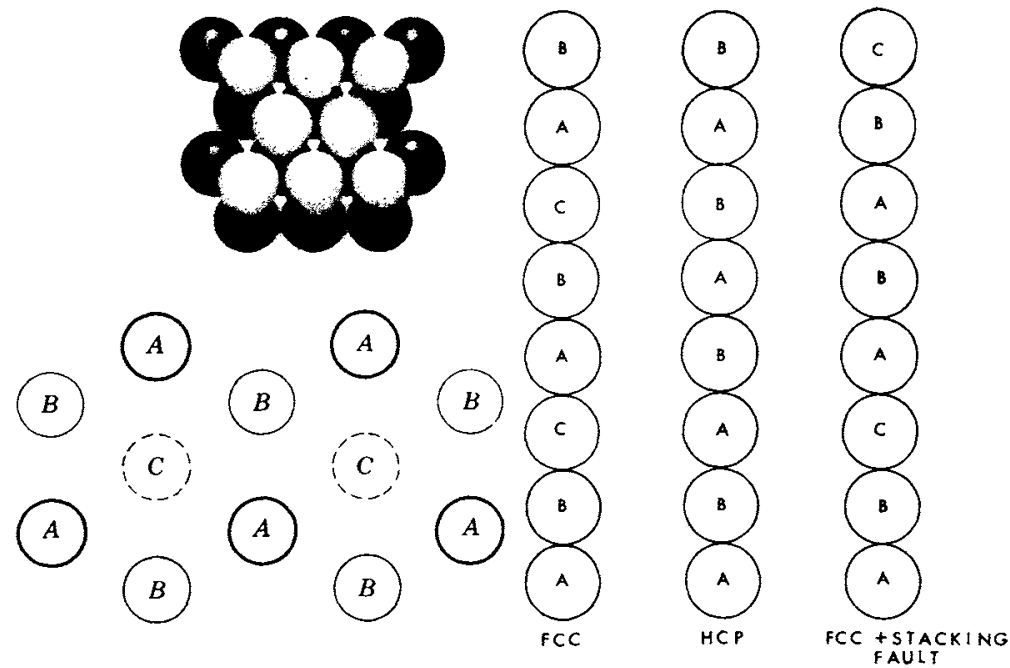

FIG 4.-Sequence of close-packed layers in cubic and hexagonal lattices. 


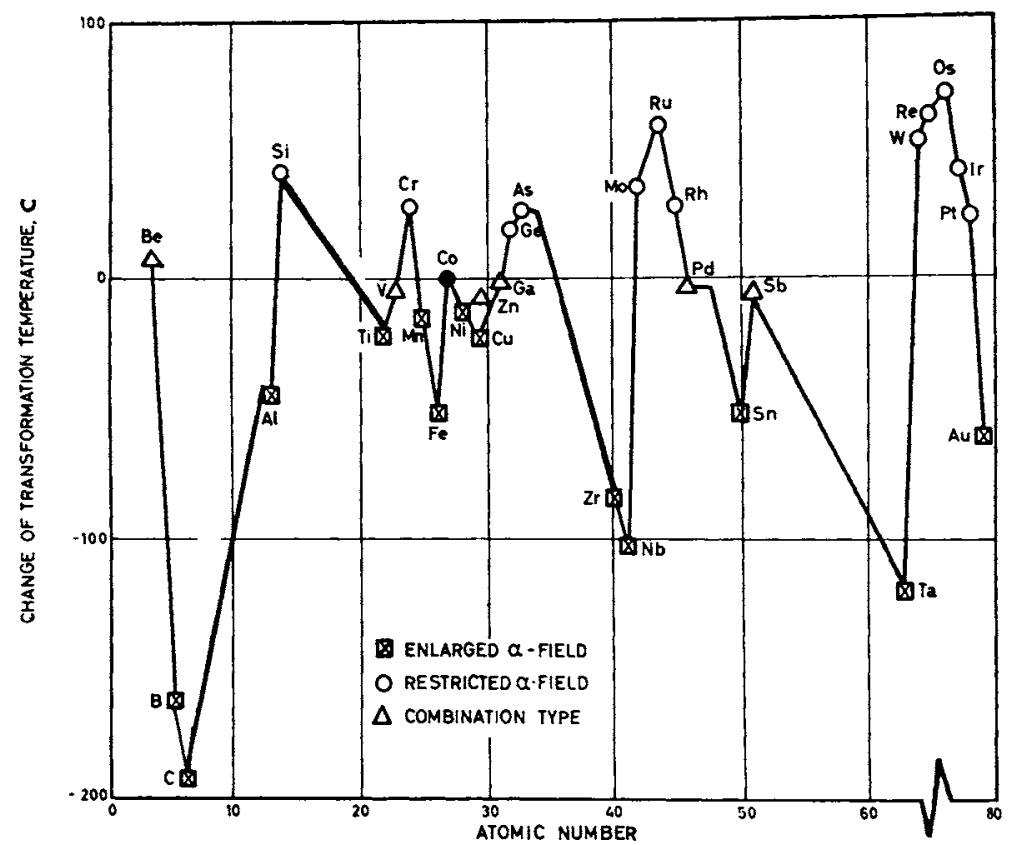

FIG 5.--Effect of addition of one atomic\% of various elements on Co transformation temperature.

ron (B), tantalum ( $\mathrm{Ta}$ ), and niobium $(\mathrm{Nb})$ are, in decreasing order, the most efficient FCC stabilizers, and molybdenum (Mo) and tungsten (W) are the HCP stabilizers. The effect of solute atoms on stacking fault energy (SFE) depends on their efficiency and on their solubility limit in Co allotrops. The solubility limits of important solute atoms are indicated in Table $1 .^{7}$

TABLE 1

Crystal Structure of Some Elements and THEIR SOLUBILITIES IN THE ALLOTROPIC ForMS OF Co

\begin{tabular}{|c|c|c|c|}
\hline \multirow[b]{2}{*}{ Element } & \multirow{2}{*}{$\begin{array}{l}\text { Crystal } \\
\text { System }\end{array}$} & \multicolumn{2}{|c|}{$\begin{array}{l}\text { Maximum Solid } \\
\text { Solubility at \% }\end{array}$} \\
\hline & & in $\epsilon \mathrm{Co}$ & in $a \mathrm{Co}$ \\
\hline B & $\mathrm{HCP}$ & $?$ & 5.0 \\
\hline $\mathrm{Al}$ & FCC & Very Small & 15.5 \\
\hline $\mathrm{Ga}$ & Orthorhombic & $7 ?$ & $7.0 ?$ \\
\hline $\mathrm{Ti}$ & HCP-BCC & 8.7 & $13.0 ?$ \\
\hline $\mathrm{C}$ & Diamond & Very Small & 4.5 \\
\hline $\mathrm{V}$ & $\mathrm{BCC}$ & $9 ?$ & 35.2 \\
\hline $\mathrm{Nb}$ & $B C C$ & Very Small & 4.5 \\
\hline Ta & BCC & $5 ?$ & $5.0 ?$ \\
\hline $\mathrm{Cr}$ & $\mathrm{BCC}$ & 40 & 41.0 \\
\hline Mo & $\mathrm{BCC}$ & 15.5 & 18.5 \\
\hline W & $\mathrm{BCC}$ & 13.5 & 17.5 \\
\hline $\mathrm{Fe}$ & $\mathrm{BCC}-\mathrm{FCC}$ & $5-6$ & Complete \\
\hline $\mathrm{Ni}$ & FCC & $5 ? ; 20 ?$ & Complete \\
\hline
\end{tabular}

The early stage of the $\alpha \rightarrow \varepsilon$ transformation in Co starts as a stacking fault. The formation of stacking faults is dependent on the SFE. The higher the SFE, the lower is the temperature for the $\alpha \rightarrow \varepsilon$ transformation and the more stable is the ductile FCC phase.

Thin film transmission electron micrographs of alloys that contain $\mathrm{Mo}$ and $\mathrm{Ta}$ are found in Figures 6 and 7 , respectively. The alloy that contains Mo (Fig 6) has a large number of stacking faults, whereas the alloy that contains $\mathrm{Ta}$ (Fig 8) is almost free of stacking faults.

Dental Co-base alloys should be designed so that their chemistry minimizes the formation of stacking faults.

AVERAGE ELECTRON HOLE NUMBER OF THE ALloY MatriX.-When the Co-base and $\mathrm{Ni}$-base alloys were developed for industrial use, it was found that the formation of certain phases, which are referred to as $\sigma, \pi, \mu$, and $R$, have a deleterious effect on the ductility of the alloys. The most harmful of these phases and the one that frequently forms in Co alloys is the $\sigma$ phase.

To control $\sigma$ phase formation, an empirical method has been introduced to deter- 


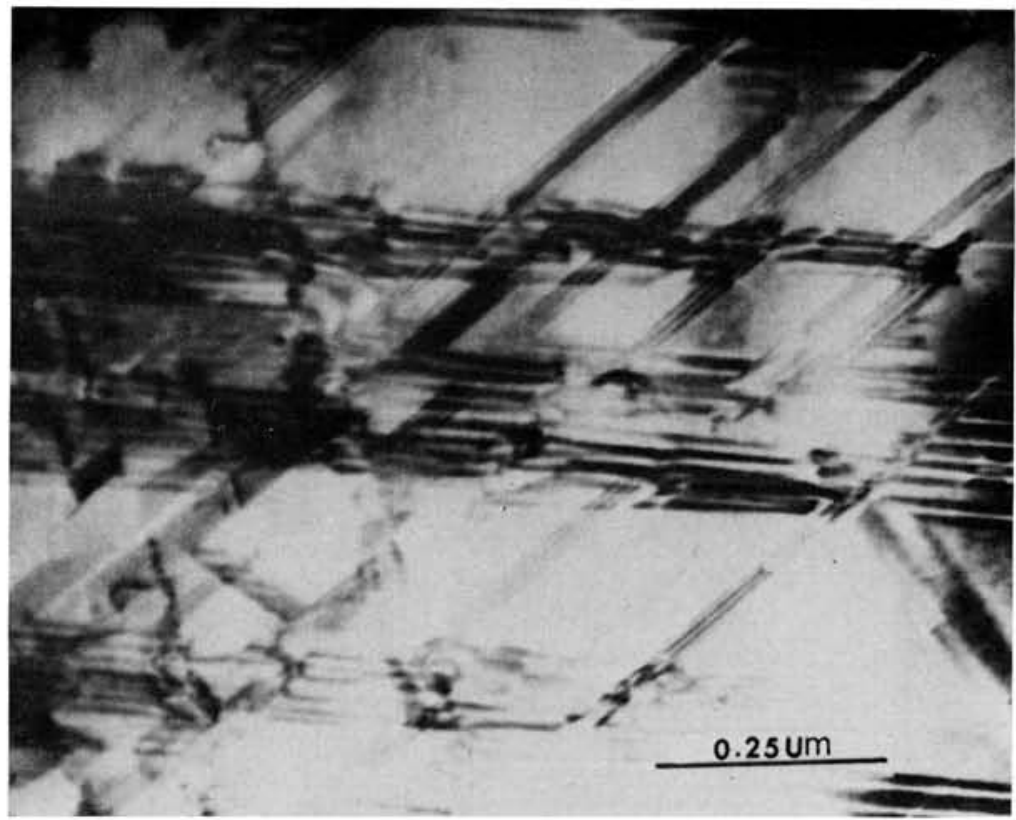

FIG 6.-Thin film transmission electron micrograph of Mo-bearing alloy shows massive stacking faults. (Courtesy of A. P. Rowe.)

mine if $\sigma$ will form in an alloy composition. This method is referred to as the phase computation method and is abbreviated as PHACOMP. 8
In 1938 Pauling ${ }^{9}$ explained the magnetic properties of the first long-period transition elements which include $\mathrm{Cr}$, manganese $(\mathrm{Mn})$, iron $(\mathrm{Fe}), \mathrm{Co}$, and $\mathrm{Ni}$. A unique

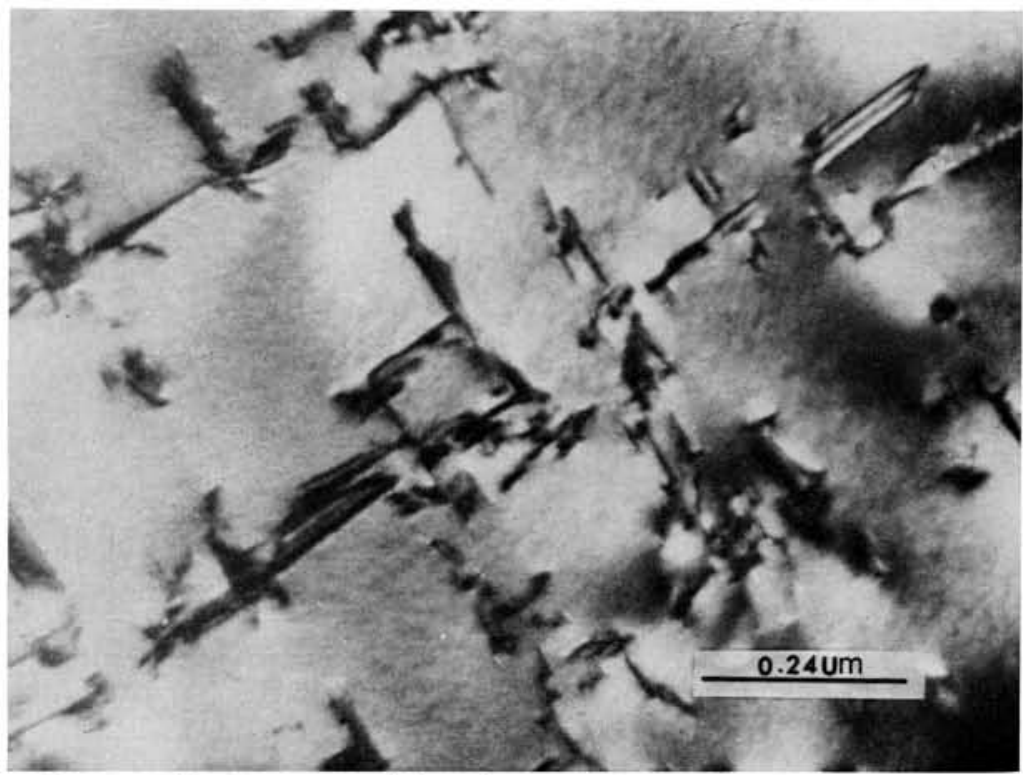

FIg 7.-Thin film transmission electron micrograph of Ta-bearing alloy shows no stacking faults. (Courtesy of A. P. Rowe.) 


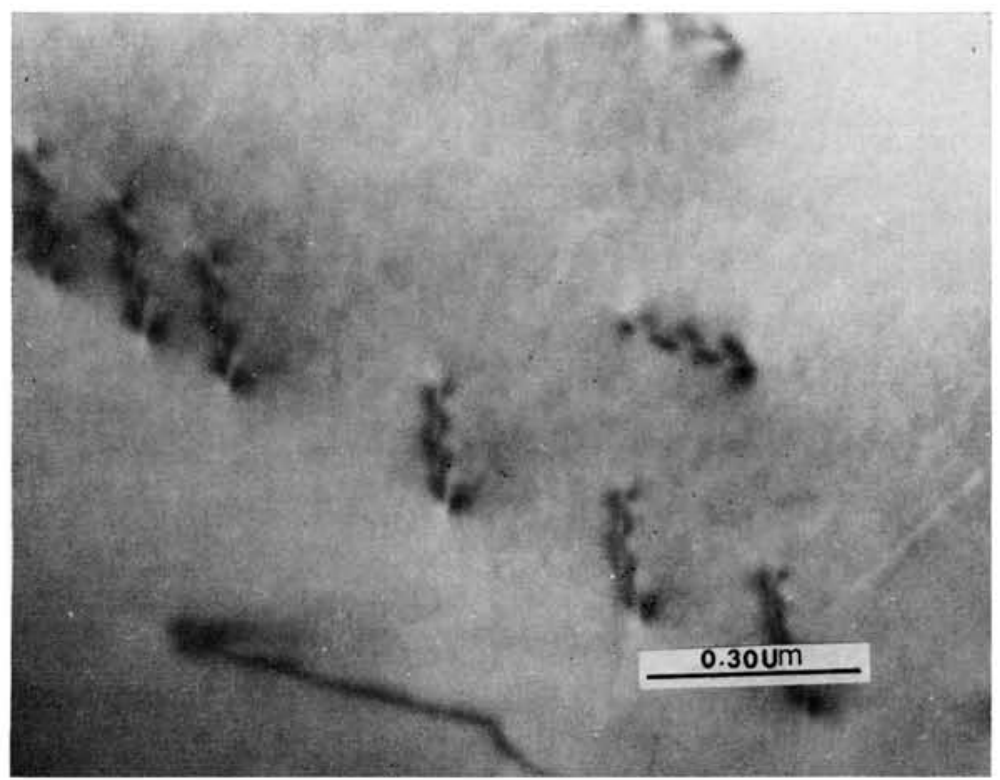

FIG 8.-Thin film transmission electron micrograph of alloy containing $7 \%$ Ta shows no $\sigma$ formation. (Courtesy of A. P. Rowe.)

feature of the transition elements is that the $3 d$ shell, which could accept ten electrons, remains partially filled, whereas some of the electrons have already occupied the $4 s$ orbitals. In addition, the atomic diameter varies insignificantly $(\sim 3 \%)$ from $\mathrm{Cr}$ to $\mathrm{Ni}$.

Pauling said the aforementioned characteristics indicate that the five $d$ orbitals of each spin could be separated into 2.44 nonbonding orbitals and 2.56 bonding orbitals. The bonding orbitals hybridize with $p$ and $s$ orbitals to account for metallic bonding. The nonbonding $d$ orbitals are then available to participate in other events. It was calculated that $\mathrm{Cr}$ requires 5.78 hybrid $(s p d)$ electrons for bonding. Because six are available in the $3 d 4 s$ orbitals, 0.22 electrons must be "left over" as nonbonding electrons. These nonbonding electrons occupy the $3 d$ nonbonding orbitals.

Pauling explained that the constancy of atomic diameter is the result of the constancy of $s p d$ bonding electrons at 5.78. Because the number of electrons available in the $3 d 4 s$ orbitals increases by one from $\mathrm{Cr}$ to $\mathrm{Mn}$ to $\mathrm{Fe}$ to $\mathrm{Co}$ to $\mathrm{Ni}$, the number of nonbonding electrons increases from 0.22 to 1.22 to 2.22 to 3.22 to 4.22 , respectively.

Pauling calculated vacancies, electron hole numbers, for the nonbonding $3 d$ or- bitals to be $4.66-\mathrm{Cr}[(2.44 \times 2)-0.22]$; $3.66-\mathrm{Mn} ; 2.66-\mathrm{Fe} ; 1.66-\mathrm{Co}$; and $0.66-$ $\mathrm{Ni}$.

PHACOMP is based on two considerations: The $\sigma$-type phases are electron compounds and their formation is dependent on the electron hole numbers $\left(N_{v}\right)$ of the elements used in the alloy. Secondly, for each alloy system there is a characteristic $\bar{N}_{v}$. Below the $\bar{N}_{v}$ not enough $\sigma$ is formed to influence the mechanical properties; above the $\bar{N}_{v}$ harmful levels of $\sigma$ form.

The average electron hole number $\left(\bar{N}_{v}\right)$ is calculated by the contents of the matrix of the alloy. The amounts of elements that are consumed by the precipitation processes are discounted during the computation of $\left(\bar{N}_{v}\right)$. The practical value of $\left(\bar{N}_{v}\right)$ of the alloys that are used for dental applications is as follows: As the value of $\bar{N}_{v}$ becomes lower, there is less concentration of the $\sigma$ type phase, and the alloy is more ductile. The composition of the alloy should be adjusted to contain larger quantities of elements with low electron hole numbers $\left(\bar{N}_{v}\right)$. For example, the alloy should have the largest possible concentration of $\mathrm{Ni}\left(N_{v}=0.66\right)$ and the least possible amount of $\mathrm{Cr}\left(N_{v}=\right.$ 4.66). Additional elements that are used for solid solution hardening (ie, remaining in 
the alloy matrix) should have a minimum $N_{v}$. In this respect, $\mathrm{Fe}\left(N_{v}=2.66\right)$ is better than $\mathrm{Ta}\left(N_{v}=5.66\right)$.

Additional elements that are used for precipitation hardening (ie, removing from the matrix) should be chosen so that the largest quantities precipitate. In this respect, $\mathrm{Ta}$ is better than $\mathrm{Fe}$. The former element reacts with $\mathrm{Co}$ and precipitates as intermetallic compounds, whereas $\mathrm{Fe}$ remains in the matrix. Additional elements that are used for precipitation hardening should have an affinity for a reaction with matrix elements of high $N_{v}$. In regard to this, C, which reacts with $\mathrm{Cr}\left(N_{v}=4.66\right)$, is better than $\mathrm{Ta}$, which reacts with Co $\left(N_{n}=1.66\right)$.

There are conflicting effects; $\mathrm{Ta}$ is a better solid solution hardener than $\mathrm{Fe}$ because it has a larger atomic diameter and a higher melting point. $\mathrm{Ta}$ is better than $\mathrm{C}$ because the latter has limited solid solubility in Co alloys. For a Co-base alloy to be strong and ductile, its composition must be a compromise of these factors.

Thin film transmission electron micrographs of two alloys that have 7 and $13 \%$ $\mathrm{Ta}$ are found in Figures 8 and 9, respectively. It is evident that the latter alloy contains $\sigma$, whereas the former is free of $\sigma$.

\section{Alloy Design}

The optimal tensile properties of Co-base alloys for dental use have not yet been established. It was thought, however, that an alloy that has a $0.2 \%$ offset yield strength of $75 \times 10^{3} \mathrm{psi}$, ductility of $10 \%$ elongation, and an ultimate tensile strength of 100 $\times 10^{3}$ psi would fulfill dental requirements.

CHOICE OF ALLOY BASE:-Corrosion resistance of superalloys has been produced by the addition of $\mathrm{Cr}$. A safe $\mathrm{Cr}$ concentration in the final alloy is $20 \%$.

The ductility of an alloy decreases as an inverse function of strengthening. This relation is not linear. The rate of change of one of these two properties is relative to the rate of change of the other. This rate is dependent on the strengthening mechanism, the SFE, the phases formed in the alloy, and their distribution.

A high SFE of a ternary Co-Cr-Ni alloy indicates that the alloy will crystallize in the ductile FCC lattice rather than in the less ductile HCP lattice. In Co-Cr-Ni alloys, $\mathrm{Cr}$ has twice the effect of $\mathrm{Ni}$ on the SFE per one atomic \%. In two ternary alloys of the same Co concentrations, the one that contains more $\mathrm{Ni}$ should be more ductile.

In the SFE theory, a minimum of $\mathrm{Cr}$ is

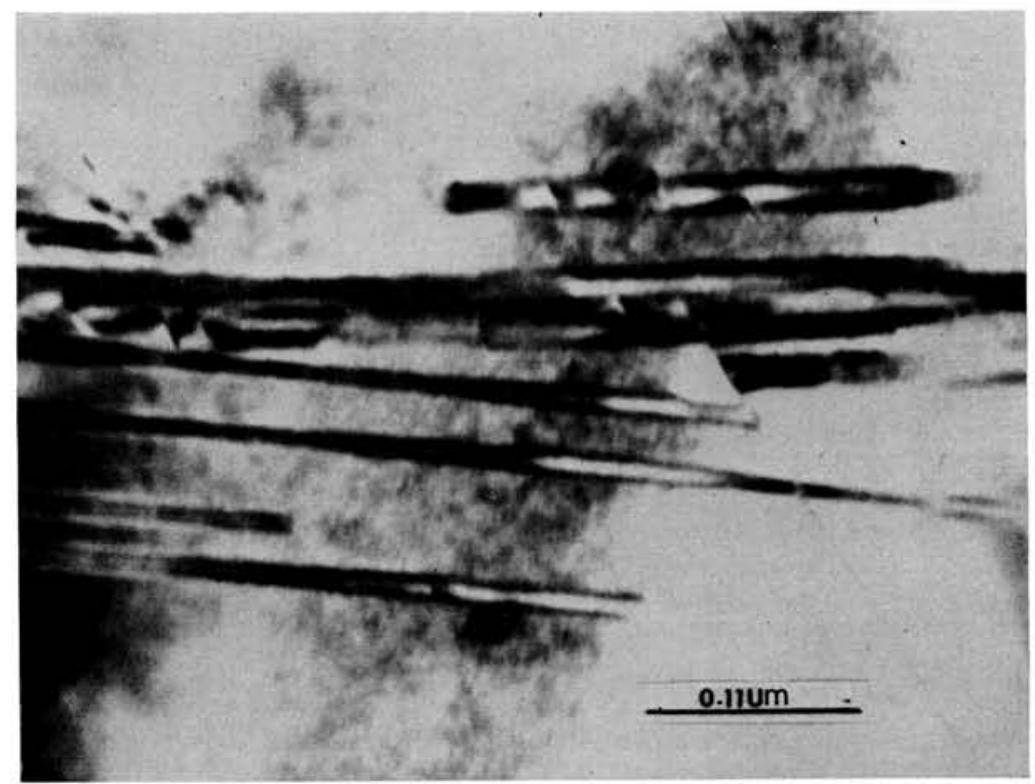

FIG 9.-Thin film transmission electron micrograph of alloy containing $13 \%$ Ta shows $\sigma$ formation. (Courtesy of A. P. Rowe.) 
used. Corrosion protection limits the $\mathrm{Cr}$ concentration in the alloy base to a minimum of about $25 \%$. To compromise for this conflict in effects, the unfavorable effect of $\mathrm{Cr}$ on the elongation should be balanced with the favorable effect of $\mathrm{Ni}$. The use of the maximum $\mathrm{Ni}$ concentration produces good elongation values.

Another factor that affects the elongation of the alloy is the precipitating phases. The phases designated as $\sigma, \pi, \mu$, and $R$ deteriorate the elongation property. The most important of these phases is the $\sigma$ phase.

The influence of $\mathrm{Cr}$ on the formation of the embrittled $\sigma$ phase was explained by PHACOMP.

The effect of $\mathrm{Cr}$ of raising the average electron hole number $\left(N_{v}\right)$ cannot be avoided. Because a $25 \% \mathrm{Cr}$ concentration was selected to be in the alloy base, a certain amount of $\sigma$ is to be expected. The amount of $\sigma$ phase that is permitted should not impair the elongation of the alloy base. It is assumed that the elongation of an alloy base will be reduced by 60 to $70 \%$ during further development. A $25 \% \mathrm{Cr}$ alloy base that has an elongation of 25 to $30 \%$ will be acceptable, regardless of the amount of $\sigma$ it contains.

The same factors that influence the elongation affect the strength property in an inverse manner. The strength increases with the $\mathrm{Cr}$ concentration and decreases when the $\mathrm{Ni}$ concentration is increased.

Although the structure of the alloy base and the nature of the phases that are formed in it are very important, it is difficult to select an alloy base for further development if only these factors are considered. This difficulty occurs because the design that produces the best elongation property results in the worst strength properties and vice versa. These factors should be considered and the selection of an alloy base should be determined by its mechanical properties. Adequate allowance for corrosion protection also should be made.

The rate at which the strength of an alloy increases is caused by a strengthening treatment. This is much slower than the rate at which the elongation property decreases; this decrease is caused by the same treatment. Therefore, an increase of more than $40 \%$ in the strength of an alloy should not be expected. To obtain a final alloy that has a $0.2 \%$ yield strength of 75 to $80 \times 10^{3}$ psi, the alloy base should have a yield strength of 45 to $50 \times 10^{3}$ psi.

As a final analysis, the selection of an alloy base should be limited by the following conditions: minimum $\mathrm{Cr}$ contents of $25 \%$; minimum elongation value of $25 \%$; minimum $0.2 \%$ yield strength of $45 \times 10^{3}$ $\mathrm{psi}$; the composition of the alloy balanced so that the formation of stacking faults or unstable FCC is minimized; and freedom from $\sigma$ formation so that the level of $\sigma$ does not interfere with the fulfillment of these mechanical properties.

An alloy base that fulfills the aforementioned requirements was chosen from the ternary phase diagram. ${ }^{10}$ The composition of the chosen alloy base is $40 \mathrm{Co}-30 \mathrm{Ni}$ $30 \mathrm{Cr}$.

CHOICE OF THE STRENGTHENING $\mathrm{MECH}-$ ANISM.-An increase in the strength of an alloy usually is accompanied by a decrease in its elongation. The relative rate of change of these two properties can vary in the same alloy system depending on the strengthening mechanism involved. The comparison of coherent and incoherent precipitates indicates that coherent precipitates are preferred for dental alloys. Strengthening precipitates in superalloy systems could be carbides or intermetallic compounds. Most carbides that form in Co-base alloys have lattice constants that are very different from the alloy matrix; therefore, the formation of lasting coherent interfaces is not to be expected. But, coherent intermetallic compound precipitates have been reported.11,12 Accordingly, the preferred strengthening mechanism for the development of dental superalloys is produced by the formation of coherent intermetallic compounds.

Choice of additional element.-Elements that are added to the ternary alloy determine the nature of the intermetallic compound. The preference is among those compounds reported in the literature; they are the intermetallic compounds of Co with titanium $\left(\mathrm{Co}_{3} \mathrm{Ti}\right),{ }^{13}$ with $\mathrm{Mo}$, with $\mathrm{Ta}\left(\mathrm{Co}_{3}\right.$ $\mathrm{Ta}),{ }^{11}$ with $\mathrm{W}\left(\mathrm{Co}_{3} \mathrm{~W}\right),{ }^{12}$ and with $\mathrm{Nb}$. There are 12 factors that determine which one of the five elements is to be selected. These factors are summarized in Table 2. According to the criteria listed in Table 2, $\mathrm{Ta}$ is the element of choice for the purpose of this study. Ludwigson ${ }^{14}$ reported that $\mathrm{Ta}$ has a long history of successful use for surgical implants because it is inert in the body. 
TABLE 2

Comparison of the Pertinent Properties of the Elements That form INTERMETALlic COMPOUNDS IN Co-CR-Ni Alloys

\begin{tabular}{|c|c|c|c|c|c|}
\hline Effect & $\mathrm{Ti}$ & $\mathrm{Ta}$ & $\mathrm{w}$ & $\mathrm{Nb}$ & Mo \\
\hline & & & In & & In \\
\hline Body compatibility & $\mathrm{E}$ & $\mathrm{E}$ & Use & & Use \\
\hline Corrosion resistance & G & $\mathrm{E}$ & & $\mathbf{P}$ & $\mathbf{P}$ \\
\hline Resistance to oxidation & & & & & \\
\hline $\begin{array}{l}\text { during alloying } \\
\text { Efficiency as a nucleating }\end{array}$ & $\mathrm{VP}$ & $\mathbf{E}$ & $\mathbf{P}$ & $\mathrm{F}$ & G \\
\hline $\begin{array}{l}\text { agent* during solidification } \\
\text { Efficiency as a solid solution }\end{array}$ & $P$ & E & E & VG & VG \\
\hline $\begin{array}{l}\text { Efficiency as a solid solution } \\
\text { hardener }{ }^{\dagger}\end{array}$ & $\mathrm{E}$ & $\mathrm{E}$ & VG & $\mathrm{E}$ & VG \\
\hline Effect on SFE & G & $\mathbf{E}$ & VP & VG & VP \\
\hline Electron hole number & & 5.66 & 4.66 & 5.66 & 4.66 \\
\hline Solubility in FCC-Co atomic $\%$ & 13 & 4.5 & 17.5 & 4.5 & 18.5 \\
\hline Solubility in HCP-Co atomic $\%$ & 8.7 & 5 & 13.5 & $<1$ & 15.5 \\
\hline Intermetallic compound with $\mathrm{Co}$ & Yes & Yes & Yes & Yes & Yes \\
\hline Fineness of precipitate & & $\mathrm{E}$ & $\mathbf{E}$ & $\mathbf{E}$ & $\cdots$ \\
\hline Cohe & & E & E & E & \\
\hline
\end{tabular}

Note: $\mathrm{E}$, excellent; $\mathrm{G}$, good; $\mathrm{F}$, fair; $\mathrm{P}$, poor; $\mathrm{V}$, very.

* Based on melting point.

+ Based on atomic radius.

\section{Conclusions}

Theoretical considerations that were supplemented by experimental data indicate that a Co-base alloy with desirable properties for dental applications is made from a $40 \mathrm{Co}-30 \mathrm{Ni}-30 \mathrm{Cr}$ matrix. This alloy is strengthened by the precipitation of coherent intermetallic compounds of Ta.

\section{References}

1. Chalmers, B.: Physical Metallurgy, New York: Wiley and Sons, 1962, p 385.

2. Shewman, P.G.: Transformations in $\mathrm{Me}$ tals, New York: McGraw-Hill, 1969, p 286.

3. Christian, J.W.: The Theory of Transformations in Metals and Alloys, New York: Pergamon Press, 1965.

4. Heidenreich, R.D., and Shockiey, W.: in Strength of Solids, Report on the Conference at the University of Bristol, July, 1947, London: The Physical Society, 1948, p 57.

5. Koster, W.: On the Influence of Elements on the Polymorphic Transformation of $\mathrm{Co}$ balt, $Z$ Metallkunde 43:297-303, 1952.

6. Hashimoto, U.: Relation Between the A1lotropic Transformation of Cobalt and Some Additional Elements, Nippon Kinzoku Gakkai-Si 1:77, 1937.
7. Cobalt (monograph), Belgium: Centre D'information Du Cobalt, 1960, p 261.

8. Rideout, S.; MANLEy, W.D.; RAMEN, E.L.; LAMENT, B.S.; and BECK, P.A.: Intermediate Phases in Ternary Alloy Systems of Transition Elements, $J$ Metals 3:872, 1951.

9. Pauling, L.: The Nature of Interatomic Forces in Metals, Physical Review 54:899, 1938.

10. JoHNSON, R.S., JR.: Determination of a Partial Room-Temperature Ternary Constitution Diagram in the As-Cast $\mathrm{Cr}-\mathrm{Co}-\mathrm{Ni}$ System Utilizing a Factorial Experimental Design, PhD dissertation, University of Michigan, 1970.

11. Drapier, J.M.; DE BRouWER, J.L.; and Coutsouradis, D.: Refractory Metals and Intermetallic Precipitates in Cobalt-Chromium Alloys, Cobalt 27:59, 1965.

12. Fritzlen, G.A.; FAULKNER, W.H.; BarRETT, B.R.; and FountaIn, R. W.: Precipitates in Cobalt-Base Alloys, Cleveland, Ohio: American Society for Metal, 1959.

13. Fountain, R.W., and Forgeng, W.D.: Phase Relations and Precipitation in Co-Ti Alloys, Trans AIME 21:998, 1959.

14. Ludwigson, D.C.: Today's Prosthetic Metals, J Metals 16:226, 1964. 